\title{
FESTIVAL AIR (SONGKRAN): KOMODIFIKASI BUDAYA DI THAILAND
}

\author{
Nikodemus Niko, Atem \\ Program Pascasarjana Sosiologi, Fakultas Ilmu Sosial dan Ilmu Politik, \\ Universitas Padjadjaran
}

nikodemusn@outlook.com

\begin{abstract}
This research aims to want to see the occurred on the discourse of cultural commodification of Songkran in Thailand. Songkran in Thailand is a religious and cultural festival, which is the celebration of New Year in Thailand. Culture of Songkran festival which then becomes bringing many foreign tourists come to some areas in Thailand like Bangkok, Chiang Mai and Phuket. This great Festival and then give effect to social, cultural as well as the economy on local community. The methods used in this study is a qualitative descriptive based on the experiences both of the author. The data analyzed i.e. secondary data that comes from a variety of scientific journals, then the primary data are analyzed based on the author's experience when on the Songkran festival in Thailand on April, 2019. Based on the analysis that the commodification of culture happens to Songkran in Thailand is not so much to erode the authenticity of rituals. This means that the core rituals such as bathing the Buddha statues in the temples still do. Commodification is a positive impact on the local community, where on area of the festival they provided tubs for sale in range $5 \mathrm{THB}$ to $15 \mathrm{THB}$. Then, foreign tourists are pouring in from various countries are also effect on the local community economy.
\end{abstract}

Keywords: commodification, Songkran Festival, culture

\begin{abstract}
Abstrak
Penelitian ini bertujuan ingin melihat wacana komodifikasi yang terjadi pada budaya Songkran di Thailand. Songkran di Thailand adalah festival keagamaan dan budaya, yang sekaligus merupakan perayaan tahun baru di Thailand. Budaya Songkran kemudian menjadi festival yang mendatangkan banyak turis asing datang ke beberapa wilayah di Thailand seperti Bangkok, Chiang Mai dan Phuket. Festival besar ini kemudian memberikan dampak kepada sosial, budaya serta ekonomi masyarakat setempat. Metode yang digunakan dalam penelitian ini adalah kualitatif deskriptif berdasarkan pengalaman penulis. Data yang dianalisis yaitu data sekunder yang berasal dari berbagai tulisan ilmiah, kemudian data primer dianalisis berdasarkan pengalaman kedua penulis mengikuti festival Songkran di Thailand pada antara
\end{abstract}


April 2019. Berdasarkan analisis bahwa komodifikasi yang terjadi pada budaya Songkran di Thailand tidak begitu banyak menggerus keaslian ritual. Artinya ritual inti seperti memandikan patung Budha di kuil-kuil masih tetap dilakukan. Komodifikasi ini berdampak positif pada masyarakat lokal, dimana pada area festival mereka menyediakan bak air untuk dijual berkisar 5 THB sampai 15 THB. Kemudian, turis asing yang berdatangan dari berbagai negara juga berdampak pada perekonomian lokal masyarakat.

Kata Kunci: komodifikasi, Festival Songkran, budaya

\section{PENDAHULUAN}

Komodifikasi budaya merupakan salah satu isu kontemporer yang berkembang seiring dengan pemikiran globalisasi di era pascamodernitas ini. Komodifikasi merupakan gambaran tentang proses barang danjasa diproduksi dengan cepat sebagai komoditas untuk kebutuhan pasar (Irianto, 2016). Pada tulisan ini membahas tentang unsur komodifikasi yang terjadi pada budaya Songkran di Thailand. Selain memuat unsur nilai ekonomi, Songkran juga memuat unsur nilai budaya dan keagamaan yang dapat disaksikan pada saat bersamaan.

Komodifikasi budaya lahir dari adanya arus globalisasi yang tak terlepas dari dampak ekonomi dan budaya sehingga komodifikasi budaya sangat erat pengaruhnya dengan pendapatan dan nilai budaya masyarakat setempat (Budiman, 2017). Dengan kata lain, dapat disebutkan bahwa komodifikasi budaya merupakan bentuk tindakan yang menjadikan unsur-unsur budaya (bahasa, sistem pengetahuan, organisasi sosial, religi dan kesenian) menjadi suatu hal yang bernilai ekonomi dan dapat diperjualbelikan sehingga menimbulkan suatu modifikasi pada unsur budaya tersebut.
Komodifikasi selalu erat dengan nilai ekonomi, kapital dan komersil. Komodifikasi mendeskripsikan cara kapitalisme melancarkan tujuannya dengan mengakumulasi kapital, atau menyadari transformasi nilai guna menjadi nilai tukar. Artinya bahwa komodifikasi ini merupakan agenda kapitalisme global yang kini tengah terjadi pada masyarakat, baik terjadi pada masyarakat lokal maupun masyarakat dunia. Pada era global hari ini, praktik budaya sudah bergeser ke media digital yang memiliki efek sangat besar bagi perkembangan pariwisata (Arifianto, 2018).

Pada masyarakat di Indonesia secara umum, dapat kita jumpai kegiatan dan ritual keagamaan yang menjadi daya tarik wisatawan. Hal ini menurut Widyastuti (2011) sudah terjadi sejak lama pada masyarakat lokal di berbagai daerah dengan tujuan meningkatkan pendapatan lokal dan memperluas lapangan kerja, namun disisi lain masyarakat lokal hanya menjadi pelaku usaha yang di dekap oleh dominasi dan hegemoni kaum kapitalis.

Hal tersebut juga terjadi pada even festival air (Songkran) di Thailand, yang sarat dengan makna meraup untung melalui banyaknya turis asing yang berdatangan ke Thailand. Berdasarkan 
Tsai dan Sakulsinlapakakorn (2016) menyebutkan bahwa terdapat top three turis asing yang paling banyak mengunjungi Thailand dari tahun ke tahun yaitu United States of America (USA), United Kingdom (UK), dan Australia.

Irianto (2016) menyebutkan bahwa pengembangan seni dan tradisi lokal merupakan salah satu tuntutan industri pariwisata, yang artinya peluang eksistensi tradisi dan lokalitas yang ada dibarengi dengan semakin berkembangnya ekonomi global. Pada tahapan inilah dituntut adanya komodifikasi budaya dalam setiap kearifan lokal yang ada. Pada sisi lain akan mengurangi kesakralan dari kearifan lokal tersebut, namun disisi lain akan mendatangkan peluang bisnis.

\section{METODE}

Penelitian ini menggunakan jenis metode penelitian kualitatif deskriptif dengan eksplorasi data sekunder dan primer. Ciri dari jenis penelitian kualitatif dapat dilihat dalam setiap kajian budaya, dimana jenis pendekatan ini menekankan pada penggalian, penjelasan, dan pendeskripsian pengetahuan secara etik, emik, dan holistik. Data sekunder dalam penelitian ini didapatkan melalui penelusuran tulisan-tulisan ilmiah seperti jurnal dan buku yang terkait dengan tema. Kemudian, data primer dieksplorasi melalui pengamatan dan interpretasi penulis pada saat festival Songkran berlangsung di Bangkok, Thailand.

\section{HASIL DAN PEMBAHASAN Komodifikasi Budaya: Isu Local Tourism di Thailand}

Thailand menyimpan kekayaan objek wisata yang penuh daya tarik. Salah satunya adalah wisata budaya Thailand yang dapat di jumpai pada tiap provinsi, seperti di Chiang Mai, Chiang Rai, Pattaya, dan Hat Yai. Tsai dan Sakulsinlapakakorn (2016) menyebutkan objek wisata Thailand yang paling banyak diminati wisatawan seperti learning tours, performing arts, festivals, cultural events, monuments sightseeing, and travel for pilgrimage. Namun, pada dasarnya tiap objek wisata yang ada sudah mengalami komodifikasi.

Komodifikasi

(commodification) menurut Barker (dalam Prajnaparamita, 2012) mendefinisikan komodifikasi sebagai proses asosiasi terhadap kapitalisme, yaitu objek, kualitas dan tanda dijadikan sebagai komoditas. Komoditas adalah sesuatu yang tujuan utamanya adalah untuk dijual ke pasar. Meminjam pemikiran Karl Marx yang memberi makna bahwa komodifikasi sebagai apapun yang diproduksi dan untuk diperjualbelikan (Evans, 2004).

Pada bahasan ekonomi politik Marxis, komodifikasi terjadi ketika nilai ekonomi yang ditugaskan untuk sesuatu yang sebelumnya tidak dipertimbangkan dalam istilah ekonominya, misalnya ide, identitas atau jenis kelamin (Evans, 2004). Bahkan pada fenomena di Thailand, seks pada anak-anak menjadi salah satu bentuk komodifikasi yang paling ekstrem (Niko, 2016).

Komodifikasi menggambarkan proses dimana sesuatu yang tidak memiliki nilai ekonomis diberi nilai dan 
karenanya bagaimana nilai pasar dapat menggantikan nilai-nilai sosial lainnya. Sebagai komoditas ia tidak hanya penting untuk berguna, tetapi juga berdaya jual. Hal ini berarti bahwa tidak ada nilai guna murni yang dihasilkan, namun hanya nilai jual, diperjualbelikan bukan digunakan. Pada pariwisata Thailand, sarat dengan unsur komodifikasi, hal ini untuk menarik kunjungan wisatawan asing ke Thailand.

Kemudian, komodifikasi budaya juga merupakan suatu proses menjadikan unsur-unsur budaya menjadi produk komoditas yang diperjualbelikan dengan motif ekonomi melalui proses produksi ulang, distribusi, dan konsumsi sehingga memudahkan konsumen memahami maksud penampilan (Hikmahwati, 2015). Pada budaya songkran di Thailand, selain menjadi sarana pengenalan budaya asli Thailand saat menyambut tahun baru, juga bermotif unsur ekonomi. Hal ini terlihat pada saat pelaksanaan songkran, warga lokal menjual air yang berkisar 5 THB sampai 15 THB per-tiap mengisi senapan air.

Pendapat lain dikemukakan oleh Setiawan(2011)menjelaskankomodifikasi adalah proses yang diasosiasikan dengan kapitalisme dimana objek, kualitas, dan tanda-tanda diubah menjadi komoditas, yaitu sesuatu yang tujuan utamanya adalah untuk dijual di pasar. Pandangan Marx (1847) tentang komoditas berakar pada orientasi materialisnya, dengan fokus pada aktifitas-aktifitas produktif pada aktor.

Pandangan Marx adalah bahwa di dalam interaksi-interaksi mereka dengan alam dan dengan para aktor lain, orang-orang memproduksi objek-objek yang mereka butuhkan untuk bertahan hidup. Proses ini di dalam kapitalisme merupakan bentuk baru sekaligus komoditas. Para aktor bukannya memproduksi untuk dirinya atau asosiasi langsung mereka, melainkan untuk orang lain (kapitalis). Produk-produk memiliki nilai tukar, artinya bukannya digunakan langsung, tapi dipertukarkan di pasar demi uang atau demi objek-objek yang lain (Ritzer \& Goodman, 2009).

Menurut Winarno (2009) di era globalisasi sekarang ini, implementasi ideologi neoliberal bersandar sangat kuat di tiga institusi global, yakni Bank Dunia, IMF, dan WTO. Bank Dunia dan IMF mengimplementasikan ideologi neoliberal melalui apa yang sering disebut sebagai Konsensus Washington yang terefleksikan dalam program-program penyesuaian struktural. Sementara WTO, mendesak agenda neoliberal melalui proyek perdagangan bebas. Kapitalismekapitalisme dunia inilah yang berimbas pada komodifikasi global sampai lokal.

Hasil-hasil pembangunan memang telah mengangkat sebagian besar penduduk dunia dari jurang kemiskinan dan keterbelakangan, yang menyebar di negara-negara seperti China, Malaysia, India, Indonesia, Korea Selatan dan juga Taiwan. Rakyat di Amerika Latin juga telah menikmati peningkatan pendapatan yang cukup signifikan, dan terangkat ekonominya jika dibandingkan dengan lima hingga enam dekade lalu (Winarno, 2009). Hal ini yang menuntut negara-negara miskin harus melakukan berbagai upaya untuk dapat bertahan, termasuk dalam hal komodifikasi sumber daya lokal seperti budaya yang menjadi objek pariwisata yang diperdagangkan.

Pandangan sosialisme, sistem ekonomi yang digunakan bersifat 
subsisten, yaitu produksi hanya untuk memenuhi kebutuhan hidup anggota masyarakat saja dan tidak untuk ditumpuk sebagai modal seperti pada sistem kapitalis (Fink, 2010). Kaum sosialis memandang bahwa sistem kapitalisme sebagai sistem yang tidak adil dan irasional, yang memang sudah seharusnya dihapuskan. Menurut Mark (1847) kapitalisme telah mengakhiri ketidakadilan dan irasionalitas feodal, namun kapitalisme telah menggantikannya dengan ketidakadilan dan irasionalitasnya sendiri (Fink, 2010).

Mark (1847) menyebutkan bahwa masyarakat sipil akan terancam krisis jika dibiarkan berjalan sendiri. Pernyataan ini memang mengandung multi-tafsir, dapat diterjemahkan bahwa masyarakat sipil (yang miskin) apabila terjadi pembiaran oleh negara maka akan terjadi suatu krisis. Krisis yang dimaksud dapat berupa krisis kemanusiaan seperti kelaparan, wabah penyakit, peperangan, dan berbagai masalah sosial lainnya. Disisi lain Hegel berpendapat bahwa negara dapat dan harus menjamin kepentingan umum daripada kepentingan-kepentingan partikular yang saling bersaing di dalam masyarakat, dan dengan demikian mencegah risiko yang mengancam sistem.

Pada saat tahun baru dan Songkran dimulai, perempuan-perempuan tua di Thailand menyiapkan dan mempersembahkan makanan untuk leluhur mereka (Claire, et. al., 2004). Lebih lanjut, Claire menekankan bahwa "it is deep within the women's hearth". Berdasarkan pengamatan penulis, tradisi persembahan makanan oleh perempuanperempuan yang sudah tua kepada leluhur ini tidak terlihat dilakukan saat Songkran di Bangkok. Hal ini juga disebutkan oleh Claire, et. al. (2004) bahwa tradisi perempuan-perempuan tua yang mempersembahkan makanan untuk leluhur ini lebih dilakukan di Chiang Mai yang merupakan pusat candi tertua yang ada di Thailand.

Euforia tahun baru dan Songkran yang ada di Bangkok sudah berubah maknanya menjadi komoditas yang berorientasi pada ekonomi. Bahkan pemerintah Thailand mengumumkan bahwa tiap orang di Thailand wajib merayakan hari libur Songkran untuk mempromosikan budaya Thailand kepada para wisatawan asing (Asian News Motivator, 2010).

\section{Songkran: Festival, Industri Wisata dan Budaya Lokal Thailand}

Thailand merupakan peninggalan kerajaan Budha yang hingga saatini masih terjaga keasliannya. Kebudayaan lokal masih begitu kental dengan kehidupan masyarakatnya, hal ini terlihat masih banyak perempuan-perempuan dan laki-laki yang memakai sarung (Sarong). Sarung wanita paling sering memiliki batas bordir pada bagian hem, sementara sarung pria lebih bercorak kotak-kotak (Chantamool, Laoakka \& Phaengsoi, 2015). Selain itu, beberapa aktivitas kebudayaan yang dilakukan tidak bisa dilepaskan dari pengaruh keagamaan yang mereka anut.

Sebagaimana diketahui mayoritas masyarakat Thailand ialah penganut Budha yang taat, mereka sangat menghormati para biksu (Buddhist monk) dan patung Buddha. Tidak sedikit ritual atautradisidilakukanuntukmenghormati dan wujud syukur kepada Budha yang 
mereka yakini sebagai zat yang suci. Wujud syukur itu dimanifestasikan oleh masyarakat dengan berbagai cara untuk mengungkapkan suka cita atas apa yang telah mereka peroleh, memanjatkan do'a serta harapan-harapan tertentu kepada Tuhan untuk kebaikan-kebaikan dimasa mendatang.

Tradisi perayaan tahun baru di Thailand dikenal dengan istilah "Songkran" yang merupakan tahun baru tradisional Thailand. Songkran dalam Bahasa Thailand berarti "pindah" atau "bertukar tempat" secara spesifik yakni perpindahan rasi bintang (zodiac) dimana matahari mulai berpindah ke Aries. Songkran juga dikenal dengan sebutan festival air (water festival) yang mengandung simbol keramah-tamahan, kasih sayang, hubungan dalam keluarga dan masyarakat secara keseluruhan (Tourism Thailand, 2015). Masyarakat Thailand meyakini bahwa air merupakan simbol yang dapat membersihkan dari hal-hal buruk atau ketidak beruntungan.

Songkran merupakan festival tahun baru yang paling popular di Thailand, diadakan pada tanggal 13-15 april setiap tahunnya (Agarwal, 2009). Tahun baru ini juga telah ditetapkan sebagai hari libur nasional, oleh karena itu momen ini menjadi kesempatan bagi orang Thailand untuk berkumpul bersama keluarga. Mereka yang berasal dari pedesaan dan bekerja di kota akan pulang dan bertemu keluarga untuk merayakan Songkran. Dalam perayaan Songkran masyarakat melakukan banyak aktivitas seperti melakukan Merit di pagi hari, lalu memberi makan para biksu dan membebaskan burung dari sangkar. Pada sore hari setelah memandikan patung Budha dengan air yang telah di beri wewangian khas Thailand (Nam Op Thai), masyarakat secara suka cita saling memercikan air atau menyemburkan air satu sama lain baik tua maupun muda (Chadchaidee, 1994).

Perayaan Songkran di tiap-tiap daerah thailand memiliki ciri khas masing-masing. Misalnya di kota besar seperti Bangkok dan Chiang Mai mereka membawa patung Budha ke jalan dan mengitari kota, di Nakhon Phanom ada ritual membuat pagoda dari pasir, sedangkan di Chiang Tung bagian paling penting dalam perayaan Songkran ialah dengan membuat patung kodok/katak dari tanah dan lumpur di pinggir sungai Khuen (Karlsson, 2013).

Menurut Yavaprapas (dalam Agarwal, 2009) bahwa festival Songkran bukanlah asli dari Thailand namun berasal dari india, asal usul festival ini digambarkan dalam bagian ajaran budha yang disebut "Sermon on Maha Songkran". itu dipercayai bahwa mitos orang india tentang Songkran dan upacara-upacara menyebar ke Thailand melaui orang Burma (Burmese) pada abad ke-11. Sejak saat itu perayaan tahun baru tradisional tersebut menjadi perhatian kerajaan Lanna kuno dengan Ciang Mai sebagai pusat atraksi atau acaranya, dari sini lah kemudian menyebar ke berbagai daerah di Thailand.

Perayaan festival tahun baru semacam ini sebenarnya tidak hanya dilakukan di Thailand, namun juga di beberapa negara asia tenggara. Hanya saja nama dan cara perayaannya yang berbeda, tetapi tetap berasal dari satu tempat yakni India. Sebutan aslinya adalah Holi yang dilakuan di seluruh India, Songkran di Thailand, Pesta Thingyan di Myanmar, Bpee Mai di Laos, Chaul 
Chnam Thmey di Kamboja, Vietnam dan Yunnan juga China (Agarwal, 2009). Namun, eksistensi festival Songkran di Thailand sudah merambah ke dunia Internasional, sehingga masyarakat dunia ingin menyaksikan dan merasakan langsung festival ini.

Perayaan Songkran dapat dikatakan bagian dari aktivitas kebudayaan yang memang sarat akan makna dan nilai yang hakekatnya bersifat sakral dengan tujuan untuk membangun hubungan sesama manusia, alam dan dengan Yang Maha Kuasa secara murni. Selain festival yang sifatnya hura-hura, Songkran bersifat sakral karena merupakan bagian dari ritual keagamaan. Namun demikian, saat ini tujuan-tujuan tersebut lebih konstruktif dan beragam di sesuaikan dengan kebutuhan-kebutuhan manusia dan dimanfaatkan untuk kepentingan tertentu.

Songkran yang semula adalah kebudayaan masyarakat lokal Thailand kemudian dikemas menjadi produk yang layak untuk dipertontonkan pada masyarakat yang lebih luas yakni masyarakat global dan lebih bersifat komersil yang tentu saja sarat akan nilai-nilai ekonomi. Dengan istiah lain kebudayaan atau tradisi Songkran saat ini telah mengalami proses komodifikasi, dimana dalam perspektif politik ekonomi komodifikasi hadir dalam bentuk-bentuk komersial yaitu negara menempatkan aturan berdasarkan standar pasar dan menetapkan aturan pasar. Pada event festival Songkran juga terdapat berbagai pilihan private party yang ditawarkan pada saat Songkran berlangsung.

Komodifikasi ini menjadi alat utama untuk mengubah relasi sosial menjadi relasi ekonomi (Curran, 1996 dalam
Widyastuti, 2011). Dengan kata lain dalam proses komodifikasi Songkran tidak bisa dilepaskan dari unsur-usur politik dan negara. Negara memegang peran penting untuk menambah atau bahkan mengubah nilai budaya agar memiliki nilai ekonomi dan menjadi produk yang layak jual sesuai standar pasar baik nasional, transnasional dan global.

Dalam proses komodifikasi biasanya akan di dukung oleh media massa sebagai alat komunikasi pemasaran baik melalui media cetak ataupun digital. Hal ini selaras dengan apa yang dilakukan oleh pemerintah Thailand melalui Tourism Authority of Thailand (TAT) dengan gencar mempromosikan Budaya Songkran sebagai salah-satu objek wisata yang paling populer di Thailand dengan menggunakan slogan "Amazing Thailand" untuk mempromosikan ke dunia internasional. Di tahun 2015 promosi pariwisata ini di lengkapi dengan kampanye "Discover Thainess" dan berhasil mendatangkan turis-turis mancanegara baik dari Asia maupun turis barat (Chantamool, Laoakka dan phaengsoi, 2015). Dampak dari upaya promosi tersebut ibu kota Thailand yakni Bangkok berhasil menempati daftar Top 10 dunia sebagai kota yang paling menarik untuk dikunjungi dan berhasil meningkatkan wisatawan dari China, USA, India dan Timur Tengah (Netherlands Embassy in Bangkok, 2017).

Saat ini Budaya memiliki daya tarik tersendiri di industri pariwisata. Menurut Richards (2005, dalam Chokriensukchai, 2015) pariwisata yang fokus pada pengalaman budaya saat ini di sebut dengan wisata budaya (cultural tourism). Wisata budaya sendiri ialah pergerakan 
seseorang ke suatu acara budaya khusus seperti situs atau peninggalan sejarah, artistik, dan manifestasi budaya, seni dan drama diluar tempat tinggal normal mereka dan pengalaman tersebut biasanya termasuk belajar unsur-unsur tertentu. Lalu UNESCO mempromosikan wisata budaya sebagai upaya memelihara kekayaan warisan dunia, (Richards, 2011). Kaitannya dengan komodifikasi Meethan (2001, dalam Chokriensukchai, 2017) memandang pariwisata sebagai bagian yang paling penting dalam proses komodifikasi dan konsumsi yang hadir dalam masyarakat yang berorientasi pasar.

Tidak dipungkiri tampaknya Thailand cukup berhasil dalam upaya mengkomersialisasikan budaya ke dalam industri pariwisata, sebagaimana diketahui industri pariwisata di Thailand menjadi sektor ekonomi yang utama yakni menyumbang sekitar 6-7\% dari pendapatan negara Thailand, pendapatan mencapai THB 2.5 triliun atau sekitar 71 miliyar USD pada tahun 2016 dengan nilai THB 1,6 triliun berasal dari pasar internasional dan THB 870 miliar dari pasar domestik (Netherlands Embassy in Bangkok, 2017). Artinya bahwa sektor pariwisata memegang peranan penting dalam peningkatan pendapatan kerajaan Thailand.

Tourism Authority of Thailand (TAT) mengungkapkan bahwa hasil pendapatan pariwisata dari kedatangan wisatawan internasional dan perjalanan domestik selama liburan Songkran 12-16 tahun 2019 menunjukkan peningkatan dengan jumlah mencapai 22.07 miliar Baht yakni peningkatan 15 persen tahun ke tahun (Tourism Thailand, 2019). Melalui industri pariwisata ini Thailand mendapatkan banyak keuntungan termasuk meningkatkan pendapatan penghasilan, membuat peluang kerja, pengentasan kemiskinan dan menstimulasi ekonomi di berbagai daerah (World Travel \& Tourism Council, 2014 dalam Tsai dan Sakulsinlapakorn, 2016). Namun dalam perspektif kritis bahwa industri pariwisata nyatanya produk kapitalis dimana dalam sistem kapitalis terdapat kepentingan-kepentingan, yakni siapa yang lebih diuntungkan dan siapa yang dirugikan?

Komodifikasi yang terjadi dalam Budaya Songkran tampak mengaburkan tujuan penyelenggaraan Songkran itu sendiri, demikan Songkran mulai ditafsirkan dengan kepentingankepentingan tertentu yakni adanya dominasi kepentingan pasar dan rekreasional. Sebagai contoh masuknya unsur dan instrumen baru dalam penyelenggaraan Songkran yakni adanya aktivitas saling tembak menggunakan pistol atau senapan air (water gun), kegiatan ini secara nyata merupakan hasil modifikasi budaya yang sebelumnya tidak pernah ada. Pistol atau senapan sendiri tidak lahir dalam kebudayaan Thailand namun merupakan produk modern yang berasal dari barat. Dengan begitu penggunaan pistol dan senapan air ini dimaksudkan untuk memenuhi standar pasar yang membuat perayaan songkran lebih layak dijual dimata internasional dan tentu saja mengarah pada kepentingan ekonomi didalamnya.

Kemudian, "air" sebagai unsur utama dalam perayaan Songkran yang mengandung nilai-nilai murni tampak menjadi bias ketika air menjadi barang yang dikomersialisasikan. Sebagaimana 
pengalaman penulis pada saat perayaan Songkran di lokasi-lokasi tertentu air tidak didapatkan secara geratis namun diperjual-belikan dengan harga 5-15 Bath sesuai dengan ukuran tabung senapan air yang digunakan. Disini penulis setuju dengan pandangan Gotham (2002, dalam Porananond, 2015) bahwa proses komodifikasi dapat memindahkan nilai tukar dalam perdagangan menjadi barang-barang atau komoditas yang dapat dihargai atau dijual. Dalam proses komodifikasi ini Songkran tidak dimaknai sebagai simbol relasi sosial yang utuh namun telah berbenturan dengan relasi ekonomi yang menimbulkan kepentingan tertentu dalam kelompokkelompok masyarakat.

\section{SIMPULAN}

Komodifikasi budaya pada festival Songkran di Thailand dapat dilihat dari adanya komersialisasi pada berbagai aspek, utamanya aspek ekonomi. Artinya festival budaya yang tadinya merupakan tradisi keagamaan dan ritual masyarakat lokal, kemudian menjadi komodifikasi yang sarat dengan nilai ekonomi/ pendapatan/kapital. Hal ini dapat dilihat dari adanya kenaikan jumlah pendapatan dari sektor pariwisata, terkhusus pada saat pelaksanaan festival Songkran di Thailand. Kenaikan jumlah wisatawan asing dalam rangka mengikuti Songkran, tidak terlepas dari bagusnya promosi pariwisata Thailand di luar negeri, utamanya pariwisata sektor budaya. Komodifikasi budaya Songkran ini tidak terlepas dari berbagai isu turisme di Thailand. Namun, pada sisi lain adanya komodifikasi budaya Songkran ini kemudian menghilangkan sebagian sedikit dari kesakralan dalam pelaksanaan ritual Songkran.

\section{DAFTAR PUSTAKA}

Agarwal. R. 2009. Water Festivals of Thailand: The Indian Connection. Silpakorn University International Journal. Vol. 9(10):7-18.

Arifianto, S. 2018. Praktik Budaya Media Digital dan Pengaruhnya. Yogyakarta: Aswaja Pressindo.

Asia News Monitor. 2010. Thailand: Songkran festival: One of the most significant elements of Thailand's cultural heritage. ProQuest Research Library. Retrieved from: http://search. proquest.com/docview/1242141233? accountid $=14526$

Budiman, A. 2017. Hubungan Komodifikasi Budaya Pertunjukan Bambu dengan Pendapatan dan Nilai Budaya Masyarakat. Bogor: Institut Pertanian Bogor.

Chadchaidee, T. 1994. Songkran Festival. Research Library. Retrieved from:http://www.tm.mahidol. ac.th/eng/academic/download/ SongkranFestival.pdf

Chantamool, A., Laoakka, S., \& Phaengsoi, K. 2015. Traditional Festivals: Development of Tourism Routes for Linking Cultural Heritage Sources in the Catchment Watershed of Mekong River Basin in Thailand. International Journal of Sociology and Anthropology. Vol. 7(11):233-245.

Chokriensukchai, K. (2017). Media Exposure to Thai Cultural Universals in Myanmar. Athens Journal of Tourism. Vol. 4 (2):147-164.

Claire, V. W., et. al. 2004. Offering: Food Tradition of Older Thai Women at Songkran. Journal of Occupational Science. Vol. 11(3):115-124.

Evans, D. S. 2004. Das Kapital untuk Pemula. Yogyakarta: Resist Book.

Fink, H. 2010. Filsafat Sosial: Dari Feodal hingga Pasar Bebas. Yogyakarta: Pustaka Pelajar.

Hikmahwati, D. N. 2015. Hubungan Komodifikasi Budaya Upacara Bersih 
Desa Singo Ulung dengan Kondisi Ekonomi Sosial Budaya Masyarakat. Bogor: Institut Pertanian Bogor.

Irianto, A. M. 2016. Komodifikasi Budaya di Era Ekonomi Global Terhadap Kearifan Lokal: Studi Kasus Eksistensi Industri Pariwisata dan Kesenian Tradisional di Jawa Tengah. Jurnal Theologia. Vol. 27(1):213-236.

Karlson, K. (2013). The Songkran Festival in Chiang Tung: A Symbolic Performance of Domination and Subordination between Lowland Tai and Hill Tai. Cultural Interaction: Thai Culture. Vol. 23(1):1-13.

Marx, K. 1847. Kemiskinan Filsafat (Terjemahan. 2007). Bogor: Hasta Mitra.

Netherlands Embassy in Bangkok. 2017. Factsheet Toerisme in Thailand. Research Library. Retrieved from: https://www.rvo.nl/sites/default/ files/2017/06/factsheet-toerisme-inthailand.pdf

Niko, N. 2016. Boy Prostitute: Kemiskinan dan Life Style. Yogyakarta: Deepublish Publishing.

Porananond, P. Tourism and the transformation of ritual practice with sand pagodas in Chiang Mai, Northern Thailand. Tourism Review. Vol. 70 (3), (2015): 165-178.

Pradjnaparamita, Z. (2012). Komodifikasi tas belanja bermerek: Motivasi dan Identitas Kaum Shopaholic Golongan Sosial Menengah Surabaya. Surabaya: Fakultas Ilmu Budaya Universitas Airlangga.

Richards G (Ed.) (2011). Cultural tourism: Global and local perspectives. New York: Routledge.
Ritzer, G., \& Goodman, D. J. 2009. Teori Sosiologi dan Teori Sosiologi Klasik sampai Perkembangan Mutakhir Teori Sosial Postmodern (terj. Nurhadi). Yogjakarta: Kreasi Wacana.

Setiawati, E. 2000. Orientasi Nilai Budaya Penghuni Pemukiman Kumuh (Studi kasus di Kampung melayu kecil, Kelurahan Bukit Duri, Kecamatan Tebet, Jakarta Selatan). Bogor: Institut Pertanian Bogor.

Tourism Thailand. 2015. Songkran Festival 2015. Research Library. Retrieved from: https://www.tourismthailand. org/fileadmin/upload_img/ Home_news/Info_of_Songkran_ Festival_2015.pdf

Tourism Thailand. 2019. Tourism Authority of Thailand Reveals 2019 Songkran. Research Library. Retrieved from: https://www.tourismthailand. org/What-news/detail/TourismAuthority-of-Thailand-reveals-2019Songkra--2987

Tsai, L. M., \& Sakulsinlapakakorn, K. 2016. Exploring Tourist's Push and Pull Travel Motivations to Participate in Songkran Festival in Thailand as a Tourist Destination: A Case of Taiwanese Visitors. Journal of Tourism and Hospitality Management. Vol. 4(5)183-197.

Widyastuti, D. A. R. 2011. Komodifikasi Upacara Religi Dalam Pemasaran Pariwisata. Jurnal Komunikasi. Vol. 1(2):197-208.

Winarno, B. 2014. Dinamika Isu-Isu Global Kontemporer. Yogyakarta: CAPS. 